\title{
Predicting the end-stage of the COVID-19 epidemic in Brazil
}

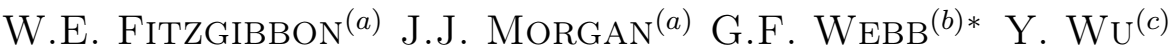 \\ ${ }^{(a)}$ Department of Mathematics, University of Houston, \\ ${ }^{(b)}$ Department of Mathematics, Vanderbilt University \\ (c) Department of Mathematics, Middle Tennessee State University
}

June 11, 2020

\begin{abstract}
We develop a dynamic model of a COVID-19 epidemic as a system of differential equations. The model incorporates an asymptomatic infectious stage and a symptomatic infectious stage. We apply the model to the current COVID-19 epidemic in Brazil. We compare the model output to current epidemic data, and project forward in time possible end-stages of the epidemic in Brazil. The model emphasizes the importance of reducing asymptomatic infections in controlling the epidemic.
\end{abstract}

2000 Mathematics Subject Classification: 34, 35K65, 92B99

Keywords: asymptomatic transmission, symptomatic transmission, turning point, final size, COVID-19 epidemic in Brazil.

\section{Model}

The epidemic population is divided into three classes: a susceptible class $S$, and two infected classes $I_{1}$ and $I_{2}$, representing the asymptomatic (or low level symptomatic) infectious individuals, and symptomatic (or high level symptomatic) infectious individuals, respectively. Susceptible individuals become asymptomatically infected via contact with either asymptomatically infectious or symptomatically infectious individuals. The transmission process is modelled by the force of infection term $S\left(\tau_{1} I_{1}+\tau_{2} I_{2}\right)$, which constitutes a loss rate for the susceptible class and a gain rate for the asymptomatic infected class. Asymptomatic individuals become symptomatic at rate $\lambda$. Symptomatic individuals are removed at rate $\gamma$, due to recovery, isolation, mortality, or other reasons. These elements lead to the following system of ordinary differential equations:

$$
\begin{aligned}
& S^{\prime}(t)=-S(t)\left(\tau_{1} I_{1}(t)+\tau_{2} I_{2}(t)\right), t \geq 0 \\
& I_{1}^{\prime}(t)=S(t)\left(\tau_{1} I_{1}(t)+\tau_{2} I_{2}(t)\right)-\lambda I_{1}(t), t \geq 0 \\
& I_{2}^{\prime}(t)=\lambda I_{1}(t)-\gamma I_{2}(t), t \geq 0 \\
& S(0)>0, I_{1}(0), I_{2}(0) \geq 0
\end{aligned}
$$

A flow diagram of the model is given in Figure 1. We remark that a model similar to (1.1) is developed in $[12,13,14,15]$, where $I_{2}$ is further differentiated into reported and unreported classes. The global dynamics of (1.1) are given in the following theorem:

Theorem 1.1 Suppose $\tau_{1}>0, \tau_{2}>0, \lambda>0$, and $\gamma>0$. Then (1.1) has bounded nonnegative solutions $S(t), I_{1}(t), I_{2}(t)$ for $t \geq 0$, and

$$
\lim _{t \rightarrow \infty} S(t)=S_{\infty}>0 \text { and } \lim _{t \rightarrow \infty} I_{i}(t)=0 \text { for } i=1,2 .
$$

This result is proved in greater generality in [11], in a setting with $S, I_{1}$ and $I_{2}$ spatially dependent, and their equations replaced by reaction-diffusion equations over a geographical domain. For the spatially homogeneous case, we can express $S_{\infty}$ and the basic reproductive number $\mathcal{R}_{0}$ in terms of the initial conditions

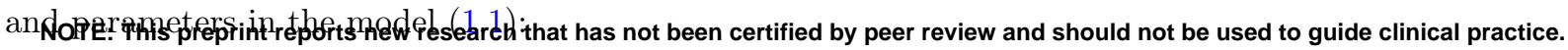

\footnotetext{
* Corresponding author
} 
Corollary $1.2 S_{\infty}$ satisfies the equation

$$
S_{\infty}=S(0) \exp \left[-\left(S(0)+I_{1}(0)+I_{2}(0)-S_{\infty}\right)\left(\frac{\tau_{1}}{\lambda}+\frac{\tau_{2}}{\gamma}\right)+\frac{\tau_{1}}{\lambda} I_{2}(0)\right]
$$

The basic reproductive number is

$$
\mathcal{R}_{0}=\frac{S_{0} \tau_{1}+\sqrt{S_{0} / \gamma} \sqrt{S_{0} \gamma \tau_{1}^{2}+4 \lambda^{2} \tau_{2}}}{2 \lambda} .
$$

Proof. From the first equation in (1.1) we obtain

$$
\begin{array}{r}
S(t)=S(0) \exp \left[-\tau_{1} \int_{0}^{t} I_{1}(s) d s-\tau_{2} \int_{0}^{t} I_{2}(s) d s\right] \\
\Rightarrow S_{\infty}=S(0) \exp \left[-\tau_{1} \int_{0}^{\infty} I_{1}(s) d s-\tau_{2} \int_{0}^{\infty} I_{1}(s) d s\right] .
\end{array}
$$

From the sum of the first, second, and third equation in (1.1) we obtain

$$
\begin{array}{r}
S^{\prime}(t)+I_{1}^{\prime}(t)+I_{2}^{\prime}(t)=-\gamma I_{2}(t) \\
\Rightarrow \int_{0}^{\infty} I_{2}(s) d s=\frac{S(0)+I_{1}(0)+I_{2}(0)-S_{\infty}}{\gamma}
\end{array}
$$

From the third equation in (1.1) we obtain

$$
\begin{array}{r}
I_{2}(t)-I_{2}(0)=\lambda \int_{0}^{t} I_{1}(s) d s-\gamma \int_{0}^{\infty} I_{2}(s) d s \\
\Rightarrow \int_{0}^{\infty} I_{1}(s) d s=\frac{\gamma \int_{0}^{\infty} I_{2}(s) d s-I_{2}(0)}{\lambda} .
\end{array}
$$

Then, (1.2) follows from (1.4), (1.5), and (1.6).

To prove (1.3) we use the next generation method $[9,10]$. The linearized equations of the infectious part of the system are

$$
\begin{aligned}
& I_{1}^{\prime}(t)=S(0)\left(\tau_{1} I_{1}(t)+\tau_{2} I_{2}(t)\right)-\lambda I_{1}(t), t \geq 0 \\
& I_{2}^{\prime}(t)=\lambda I_{1}(t)-\gamma I_{2}(t), t \geq 0
\end{aligned}
$$

The corresponding matrix is

where

$$
A=\left[\begin{array}{cc}
S(0) \tau_{1}-\lambda & S(0) \tau_{2} \\
\lambda & -\gamma
\end{array}\right]=V-S
$$

$$
V=\left[\begin{array}{cc}
S(0) \tau_{1} & S(0) \tau_{2} \\
\lambda & 0
\end{array}\right], \quad S=\left[\begin{array}{ll}
\lambda & 0 \\
0 & \gamma
\end{array}\right]
$$

The next generation matrix is

$$
V S^{-1}=\left[\begin{array}{cc}
S(0) \tau_{1} / \lambda & S(0) \tau_{2} / \gamma \\
1 & 0
\end{array}\right]
$$

Then, $\mathcal{R}_{0}$ in (1.3) is the dominant eigenvalue of $V S^{-1}$.

\section{COVID-19 in Brazil}

We apply this result to the COVID-19 epidemic in Brazil. Other models of the COVID-19 epidemic in Brazil are in $[1,2,3,4,5,6,7,8,16,17,18,19,20]$. Currently, the epidemic in Brazil is in a rapid growth phase, with limited social distancing measures in effect, and limited compliance with these measures. We use the cumulative daily reported cases data for this epidemic from the Ministério da Saúde of Brazil (https://coronavirus.saude.gov.br/).

We set the time units to days. We view $I_{1}(t)$ as the population of asymptomatic or low level symptomatic infectious individuals at time $t$. We view $I_{2}(t)$ as the population of high level symptomatic infectious individuals at time $t$. We set $S(0)=210,000,000$, the current population of Brazil. We set the loss rate 
medRxiv preprint doi: https://doi.org/10.1101/2020.05.28.20116103; this version posted June 12, 2020. The copyright holder for this preprint (which was not certified by peer review) is the author/funder, who has granted medRxiv a license to display the preprint in perpetuity. It is made available under a CC-BY 4.0 International license.

\begin{tabular}{ccccccccccc}
\hline 17 & 18 & 19 & 20 & 21 & 22 & 23 & 24 & 25 & 26 & 27 \\
\hline 291 & 428 & 621 & 904 & 1128 & 1546 & 1891 & 2201 & 2433 & 2915 & 3417 \\
\hline 28 & 29 & 30 & 31 & & & & & & & \\
\hline 3903 & 4256 & 4579 & 5717 & & & & & & & \\
\hline
\end{tabular}

Table 1: March - cumulative reported cases in Brazil.

\begin{tabular}{cccccccccc}
\hline 1 & 2 & 3 & 4 & 5 & 6 & 7 & 8 & 9 & 10 \\
\hline 6834 & 7910 & 9056 & 10278 & 11130 & 12056 & 13717 & 15927 & 17857 & 19638 \\
\hline 11 & 12 & 13 & 14 & 15 & 16 & 17 & 18 & 19 & 20 \\
\hline 20727 & 22169 & 23430 & 25262 & 28320 & 30425 & 33682 & 36599 & 38654 & 40581 \\
21 & 22 & 23 & 24 & 25 & 26 & 27 & 28 & 29 & 30 \\
\hline 43079 & 45757 & 49492 & 52995 & 58509 & 61888 & 66501 & 71886 & 78162 & 85380 \\
\hline
\end{tabular}

Table 2: April - cumulative reported cases in Brazil.

$\lambda$ of $I_{1}(t)$ to $1 / 7$ per day, which means $I_{1}$ infectiousness lasts 7 days on average. We set the loss rate $\gamma$ of $I_{2}(t)$ to $1 / 7$ per day, which means $I_{2}$ infectiousness lasts 7 days on average. We believe the values $\lambda=7$ and $\gamma=7$ are reasonable estimates at this time for the current COVID-19 epidemic in Brazil. We identify an interval of time $\left[t_{0}, t_{1}\right]$ on which the cumulative daily reported cases data is growing: $t_{0}=1$, corresponding to March 17 and $t_{1}=75$, corresponding to May 30 .

The cumulative number $I_{1}(t)$ of low level infectious cases as a function of time $t$ is $\int_{t_{0}}^{t} S(s)\left(\tau_{1} I_{1}(s)+\right.$ $\left.\tau_{2} I_{2}(s)\right) d s$. The cumulative number $I_{2}(t)$ of high level infectious cases as a function of time $t$ is $\lambda \int_{t_{0}}^{t} I_{1}(s) d s$. The high level infectious cases $I_{2}$ are removed at the rate $\gamma$ per day. We assume that a fraction $f=0.3$ of these removed cases are reported, isolated, and cause no further transmissions. Thus, the cumulative number of reported cases at time $t$ is $f \gamma \int_{t_{0}}^{t} I_{2}(s) d s$, with $f=0.3$ and $\gamma=1 / 7$. Other fractional values $f$ could be assumed, but currently this fractional value is not known.

We fit the parameters $\tau_{1}, \tau_{2}$, and initial values $I_{1}\left(t_{0}\right), I_{2}\left(t_{0}\right)$, so that the solutions of (1.1) align with the cumulative reported cases data on the time interval $\left[t_{0}, t_{1}\right]$. For this time interval, we estimate $\tau_{1}=$ $2.5 \times 10^{-10}, \tau_{2}=1.0 \times 10^{-9}, I_{1}\left(t_{0}\right)=13,000, I_{2}\left(t_{0}\right)=8,200$, by fitting the solutions of $(1.1)$ to the cumulative reported cases data between March 17 and May 30. This means that 25\% of transmissions are due to $I_{1}$ asymptomatic or low level symptomatic cases, in this stage of the epidemic, in which the number of daily reported cases in increasing. In Figure 2 we graph the cumulative reported cases data and the cumulative reported cases from the simulation of the model. Other choices of the parameters and initial values are possible.

The daily reported cases from the model simulation, with $f=0.3, \gamma=1 / 7, t_{0}=1$ (March 17), is obtained by solving the differential equation

$$
D R^{\prime}(t)=f \gamma I_{2}(t)-D R(t), t \geq t_{0}, \quad D R\left(t_{0}\right)=D R_{0}=291
$$

In Figure 3 we graph the daily reported cases data and the daily reported cases from the model simulation with $f=0.3, \gamma=1 / 7$ and $t_{0}=1$ (March 17 ).

In Figure 4 we project forward in time the model simulation of the cumulative reported cases $f \gamma \int_{t_{0}}^{t} I_{2}(s) d s$, the model simulation of the total cumulative $I_{1}(t)$ cases $\int_{t_{0}}^{t}\left(\tau_{1} I_{1}(s)+\tau_{2} I_{2}(s)\right) S(s) d s$, and the model simulation of the total $I_{2}(t)$ cases $\int_{t_{0}}^{t} \lambda I_{1}(s) d s$. The final size of the epidemic is approximately 157,000, 000 cases. The turning points of the cumulative cases are the times at which the graphs transition from concave up to concave down. The turning points are obtained by setting the second derivative of these graphs to 0 . The turning points are graphed as vertical lines. The turning point of the cumulative $I_{2}$ cases is approximately one week later than the turning point of the cumulative $I_{1}$ cases, which is consistent with the assumption that the average time of $I_{1}$ infectiousness $1 / \lambda=7$ days. The turning point of the reported cumulative $I_{2}$ cases is approximately one week later than the turning point of the cumulative $I_{2}$ cases, which is consistent with the assumption that the average time of $I_{2}$ infectiousness $1 / \gamma=7$ days.

The extremely high number of cases projected in the simulation, with on-going unaltered transmission rates, is very unlikely. It is certain that government imposed and socially adopted distancing measures will take effect, and mitigate transmission. Such social distancing measure result in reduction of both $\tau_{1}$ and $\tau_{2}$. Measures such as isolation and contact tracing of high level symptomatic $I_{2}$ cases, and quarantining of low level symptomatic $I_{1}$ cases, can be quantified in terms of the final size formula (Corollary 1.2) of the 
medRxiv preprint doi: https://doi.org/10.1101/2020.05.28.20116103; this version posted June 12, 2020. The copyright holder for this preprint

(which was not certified by peer review) is the author/funder, who has granted medRxiv a license to display the preprint in perpetuity.

It is made available under a CC-BY 4.0 International license .

\begin{tabular}{cccccccccc}
\hline 1 & 2 & 3 & 4 & 5 & 6 & 7 & 8 & 9 & 10 \\
\hline 91299 & 96396 & 101147 & 107780 & 114715 & 125218 & 135106 & 145328 & 155939 & 162699 \\
\hline 11 & 12 & 13 & 14 & 15 & 16 & 17 & 18 & 19 & 20 \\
\hline 168331 & 177589 & 188974 & 202918 & 218223 & 233142 & 241080 & 254220 & 271628 & 291579 \\
\hline 21 & 22 & 23 & 24 & 25 & 26 & 27 & 28 & 29 & 30 \\
\hline 310087 & 330890 & 347398 & 363211 & 374898 & 391222 & 411821 & 438238 & 465166 & 498440 \\
\hline
\end{tabular}

Table 3: May - cumulative reported cases in Brazil.

epidemic. The reduction of $\tau_{2}$, corresponds to the identification and isolation of $I_{2}$ high level symptomatic cases. The reduction of $\tau_{1}$, corresponds to the contact tracing of $I_{2}$ high level symptomatic cases, and monitoring and quarantining of those contact traced $I_{1}$ asymptomatic or low level symptomatic cases. The formula (1.2) for $S_{\infty}$ in Corollary 1.2 can be used to estimate the effects of these mitigations. The values of the initial conditions in formula (1.3) can be reset to up-dated values, with modified parameters $\tau_{1}, \tau_{2}$, to give time-forward predictions of the final size $S_{0}-S_{\infty}$. The spatially homogeneous model (1.1) can thus be used to predict the final size of the epidemic in Brazil, as new data becomes available, corresponding to social distancing changes in the population.

In Figure 5 we use formula (1.2) to graph the final size $S_{0}-S_{\infty}$ as a function of the $I_{1}$ transmission rate $\tau_{1}$ and the $I_{2}$ transmission rate $\tau_{2}$. We assume that the initial values $I_{1}(0)=13,000$ and $I_{2}(0)=8,200$, and the parameters $\lambda=1 / 7$ and $\gamma=1 / 7$ are at baseline values. If the transmission rate $\tau_{1}$ of low level infectious individuals $I_{1}$ is reduced to $1.5 \times 10^{-10}$, and the transmission rate $\tau_{2}$ of high level infectious individuals $I_{2}$ is reduced to $0.6 \times 10^{-9}$, then the final size $S(0)-S_{\infty}$ of the epidemic is approximately $38,000,000$ cases. The effects of various transmission rate reductions can be viewed in the graph.

In Figure 6 we graph the final size $S_{0}-S_{\infty}$ as a function of the transmission parameters $\tau_{1}$ and $\tau_{2}$, with one fixed at baseline, and the other decreasing from baseline. We assume the initial values $I_{1}(0)=$ $I_{1}\left(t_{1}\right)=969,000$ and $I_{2}(0)=I_{2}\left(t_{1}\right)=692,000$ in formula $(1.3)$ are reset values at time $t_{1}=$ May 30 , in the baseline model simulation. We assume $\lambda=1 / 7$ and $\gamma=1 / 7$ are at baseline values. The reduction of the symptomatic class $I_{2}$ transmission rate $\tau_{2}$ has greater effect in reducing the final size, than the reduction of the asymptomatic class $I_{I}$ transmission rate $\tau_{1}$, because prior to May $30, I_{2}$ transmissions were largely unrestrained by distancing measures.

In Figure 7 we graph the basic reproductive number $\mathcal{R}_{0}$ in formula (1.3) as a function of the transmission parameters $\tau_{1}$ and $\tau_{2} . \mathcal{R}_{0}$ is, approximately, the number of transmissions generated by one infectious individual in the outbreak stage of the epidemic. The reduction of the symptomatic class $I_{2}$ transmission rate $\tau_{2}$ has greater effect in reducing $\mathcal{R}_{0}$, than the reduction of the asymptomatic class $I_{I}$ transmission rate $\tau_{1}$, because prior to May 30, $I_{2}$ transmissions were largely unrestrained by distancing measures.

\section{Conclusions}

We have developed a dynamic model of a COVID-19 epidemic outbreak in a susceptible population. Our model describes the outbreak as a growth of transmission of susceptible individuals from two classes of infectious individuals: $I_{1}$ asymptomatic (low level symptomatic), and $I_{2}$ symptomatic (high level symptomatic). The model does not assume that major government measures or social behaviour changes have been implemented to mitigate the epidemic transmission. The model also assumes that reported cases are a fraction of the total cases in the population.

We apply the model to the COVID-19 current in Brazil. We identify parameters and initial conditions that give agreement of the model output with current case data from Ministério da Saúde of Brazil. We project forward in time the model solutions, to give final size predictions of the epidemic in the absence of social distancing measures. The extreme scenario that the epidemic continues, without social distancing mitigation, is extremely unlikely, given the magnitude of this final size. Intervention measures, such as isolation and contact tracing of high level symptomatic $I_{2}$ cases, and quarantining of low level symptomatic $I_{1}$ cases, can be quantified in terms of the final size formula (Corollary 1.2) of the epidemic. The reduction of $\tau_{2}$, corresponds to the identification and isolation of $I_{2}$ high level symptomatic cases. The reduction of $\tau_{1}$, corresponds to the contact tracing of $I_{2}$ high level symptomatic cases and quarantining of contact traced $I_{1}$ asymptomatic or low level symptomatic cases. Both measures have major effect in controlling the epidemic. 
medRxiv preprint doi: https://doi.org/10.1101/2020.05.28.20116103; this version posted June 12, 2020. The copyright holder for this preprint (which was not certified by peer review) is the author/funder, who has granted medRxiv a license to display the preprint in perpetuity.

It is made available under a CC-BY 4.0 International license .

\section{References}

[1] L. R. P. de Alcantara, L. Silva, A. R. de Alcantara, et al., Using different epidemiological models to modeling the epidemic dynamics in Brazil, medRxiv 2020.04.29.20085100; doi: https://doi.org/10.1101/2020.04.29.20085100.

[2] G.B. de Almeida, T. Vilches, C. Ferreira, et al., Several countries in one: a mathematical modeling analysis for COVID-19 in inner Brazil, medRxiv 2020.04.23.20077438.

[3] A. Arenas, W. Cota, J. Gómez-Gardeñes et al., A mathematical model for the spatiotemporal spreading of COVID-19, medRxiv, doi: https://doi.org/10.1101/2020.03.21.20040022.

[4] S.B. Bastos and D.O. Cajueiro, Modeling and forecasting the early evolution of the Covid-19 pandemic in Brazil, arXiv preprint arXiv:2003.14288, 2020.

[5] A. Canabarro, E. Tenorio, R. Martins, et al., Data-driven study of the COVID-19 pandemic via agestructured modelling and prediction of the health system failure in Brazil amid diverse intervention strategies, medRxiv 2020.04.03.20052498; doi: https://doi.org/10.1101/2020.04.03.20052498.

[6] C. Castilho, J. A. M. Gondim, M. Marchesin, and M. Sabeti, Assessing the efficiency of different control strategies for the coronavirus (COVID-19) epidemic, arXiv:2004.03539v1 [q-bio.PE]

[7] R.M. Cotta, C.P. Naveira-Cotta, and P. Magal, Parametric identification and public health measures influence on the COVID-19 epidemic evolution in Brazil, medRxiv 2020.03.31.20049130; doi: https://doi.org/10.1101/2020.03.31.20049130.

[8] N. Crokidakis, Data analysis and modeling of the evolution of COVID-19 in Brazil, https://www.researchgate.net/publication/340270886.

[9] O. Diekmann, J.A.P. Heesterbeek, and J.A.J. Metz, On the definition and the computation of the basic reproduction ratio R0 in models for infectious diseases in heterogeneous populations, J. Math. Biol., 28 (1990), 365-382.

[10] P. van den Driessche, and J. Watmough, Reproduction numbers and sub-threshold endemic equilibria for compartmental models of disease transmission, Math.Bios., 180(2002), 29-48.

[11] W.E. Fitzgibbon, J.J. Morgan, G.F. Webb, and Y. Wu, Analysis of a reaction-diffusion disease model with asymptomatic transmission, submitted for publication.

[12] Z. Liu, P. Magal, O. Seydi, and G.F. Webb, Understanding unreported cases in the 2019-nCov epidemic outbreak in Wuhan, China, and the importance of major public health interventions, MPDI Biology, (2020), 9(3), 50 .

[13] Z. Liu, P. Magal, O. Seydi, and G.F. Webb, Predicting the cumulative number of cases for the COVID19 epidemic in China from early data, Math. Biosci. Eng., 17(4) (2020), 3040-3051.

[14] Z. Liu, P. Magal, O. Seydi, and G.F. Webb, A COVID-19 epidemic model with latency period, Infect. Dis. Mod., 5 (2020), 323-337.

[15] Z. Liu, P. Magal, O. Seydi, and G.F. Webb, A model to predict COVID-19 epidemics with applications to South Korea, Italy, and Spain, SIAM News, May (2020).

[16] O.P. Neto, J.C. Reis, A.C.E. Brizzi, et al., COVID-19 mathematical model reopening scenarios for São Paulo - Brazil, medRxiv preprint.

[17] J.H. Sales, Epidemic COVID mathematical model, Int. J. Lat. Res .Sci. Tech., 72(2) (2020),1-5.

[18] P. Savi, M.A. Savi, and B. Borges, A mathematical description of the dynamics of the coronavirus disease 2019 (COVID-19): a case study of Brazil, http://arxiv.org/abs/2004.03495.

[19] R.A. Schulz, C.H. Coimbra-Araújo, and S.W. Costiche, COVID - 19: A model for studying the evolution of contamination in Brazil, arXiv.org > q-bio > arXiv:2003.13932.

[20] G.L. Vasconcelos, A.M.S. Macêdo, R.l. Ospina, et al., Modelling fatality curves of COVID19 and the effectiveness of intervention strategies, medRxiv 2020.04.02.20051557; doi: https://doi.org/10.1101/2020.04.02.20051557. 
medRxiv preprint doi: https://doi.org/10.1101/2020.05.28.20116103; this version posted June 12, 2020. The copyright holder for this preprint (which was not certified by peer review) is the author/funder, who has granted medRxiv a license to display the preprint in perpetuity.

It is made available under a CC-BY 4.0 International license .

\section{Figures}

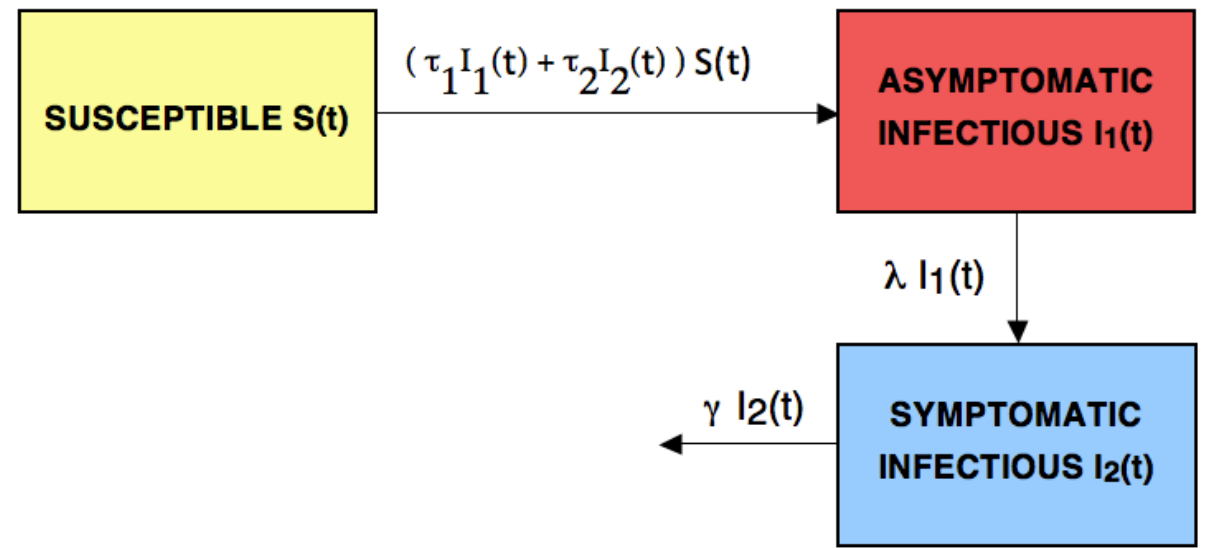

Figure 1: Flow diagram of the model.

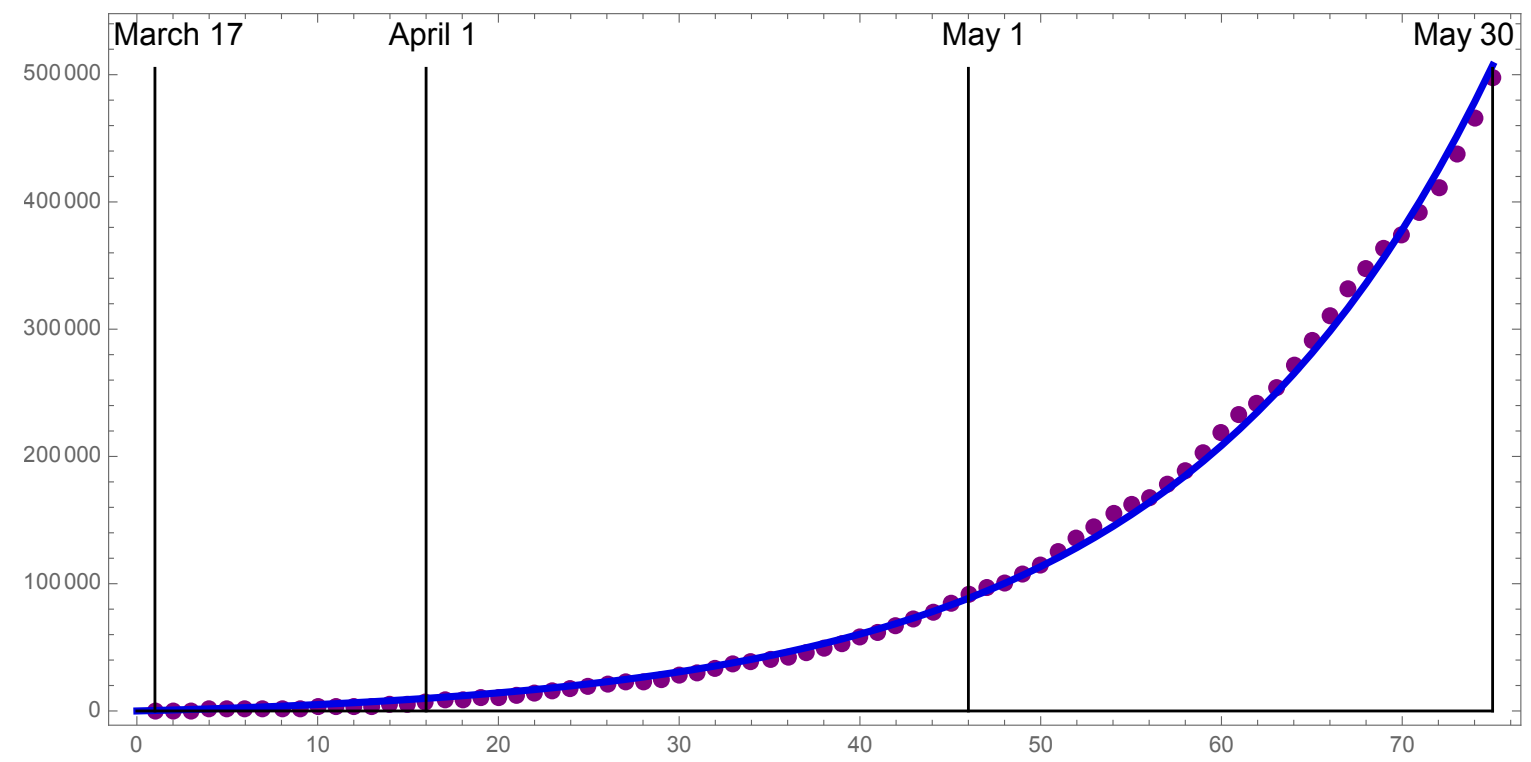

Figure 2: Dots: cumulative reported cases data from Tables 1,2,3. Graph: model simulation of the cumulative reported cases $f \gamma \int_{t_{0}}^{t} I_{2}(s) d s$, with $f=0.3$ and $\gamma=1 / 7 . f$ is the fraction of removed $I_{2}$ cases that are reported. 
medRxiv preprint doi: https://doi.org/10.1101/2020.05.28.20116103; this version posted June 12, 2020. The copyright holder for this preprint (which was not certified by peer review) is the author/funder, who has granted medRxiv a license to display the preprint in perpetuity.

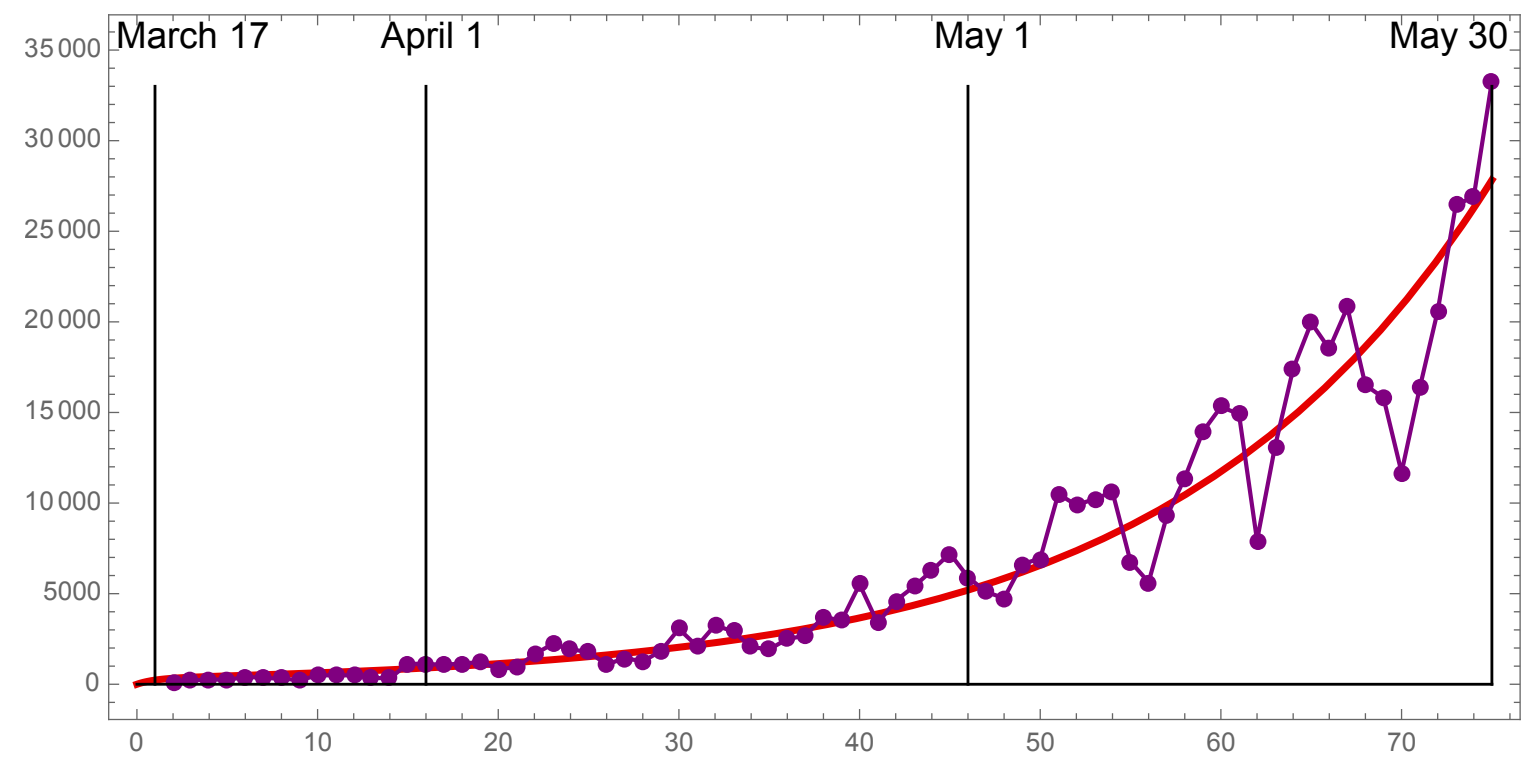

Figure 3: Dots: daily reported cases data obtained by subtraction day by day from the data in Tables 1,2,3. Graph: model simulation of the daily reported cases $D R(t)$ with $f=0.3, \gamma=1 / 7$, and $t_{0}=1$ (March 17 ).

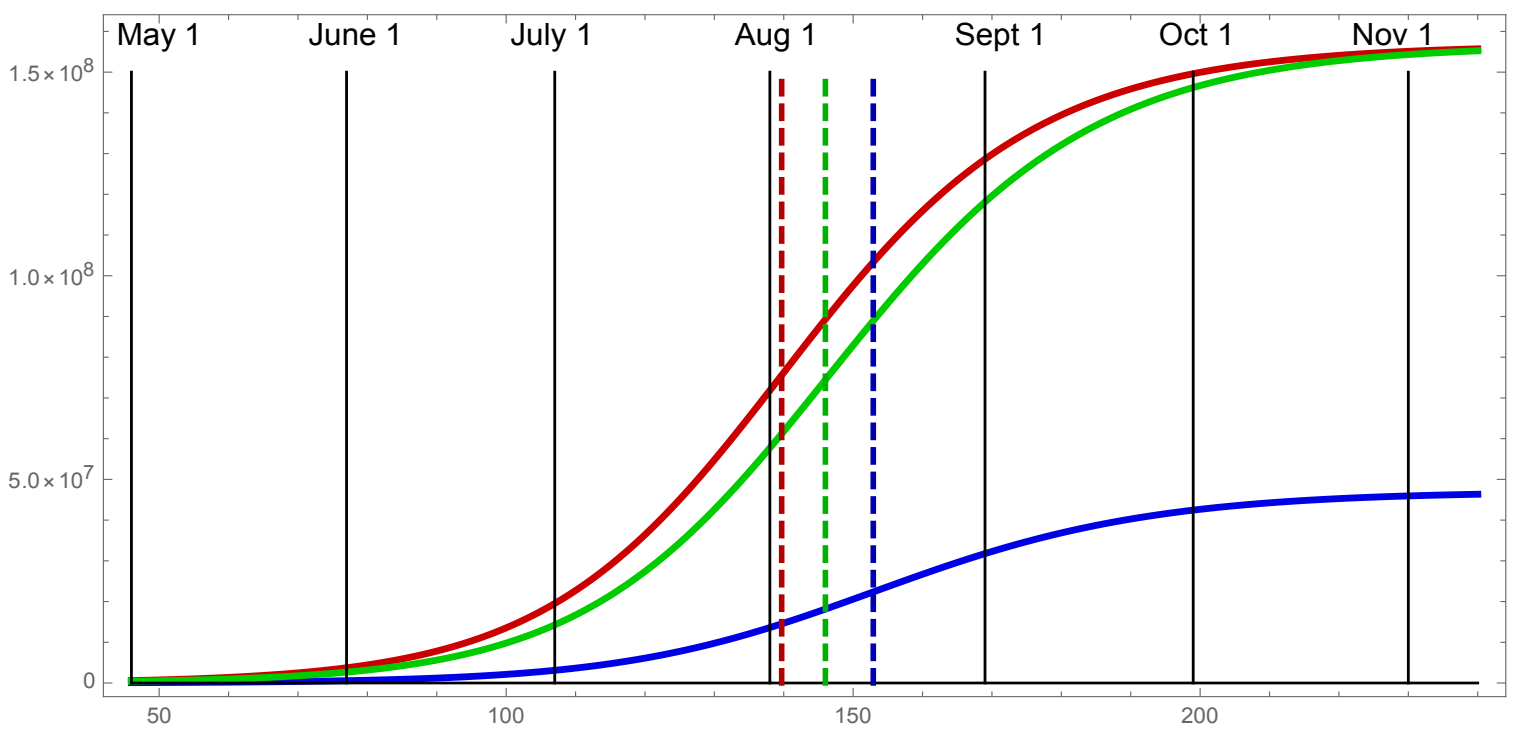

Figure 4: Blue: model simulation of the cumulative reported cases. Red: model simulation of the cumulative $I_{1}$ infectious cases. Green: model simulation of the cumulative $I_{2}$ infectious cases. The turning point of the cumulative reported cases is approximately day 152.6, the turning point of the cumulative $I_{1}$ cases is approximately day 139.5, and the turning point of the cumulative $I_{2}$ cases is day 146 . The $\lim _{t \rightarrow \infty} I_{2}(t)$ is approximately 157,000,000 cases. 
medRxiv preprint doi: https://doi.org/10.1101/2020.05.28.20116103; this version posted June 12, 2020. The copyright holder for this preprint (which was not certified by peer review) is the author/funder, who has granted medRxiv a license to display the preprint in perpetuity.

It is made available under a CC-BY 4.0 International license .

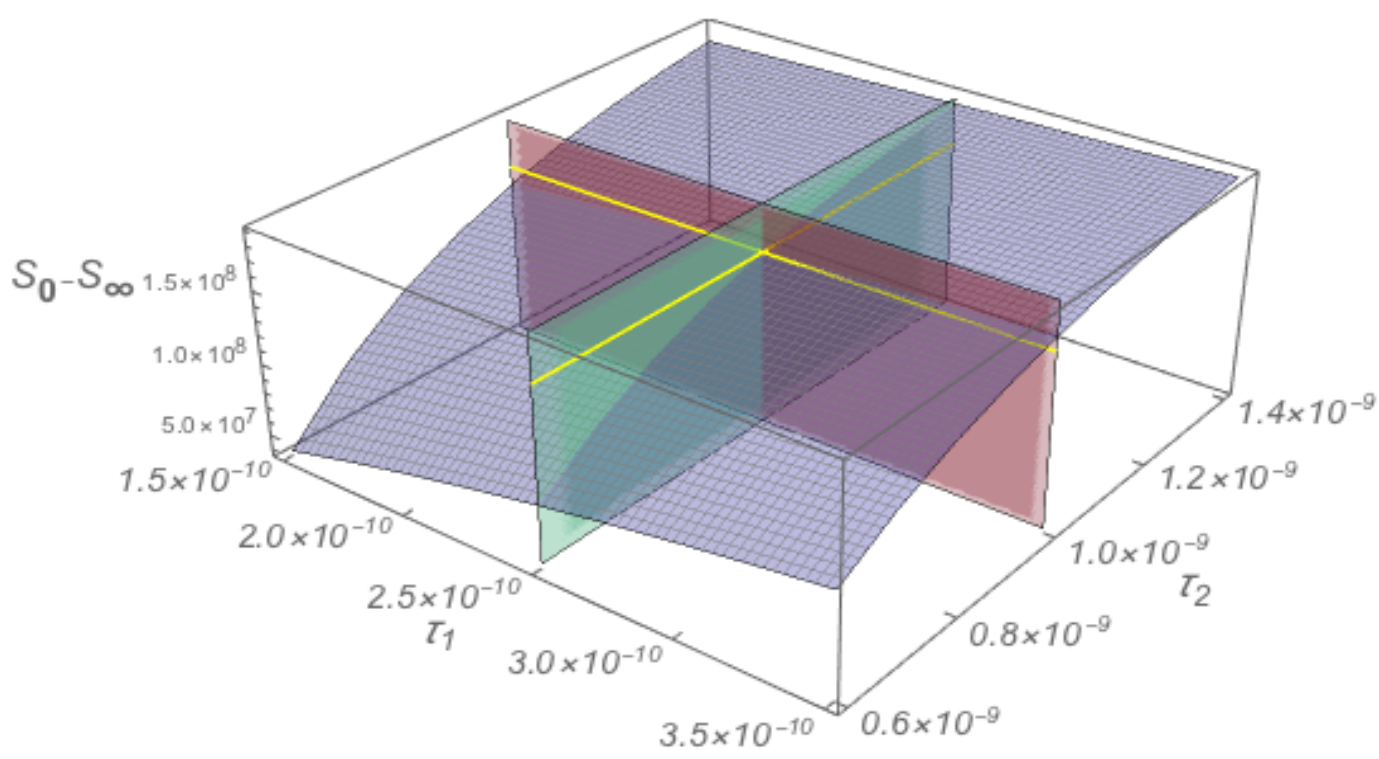

Figure 5: Blue surface: final size $S_{0}-S_{\infty}$ graphed as a function of of the transmission parameters $\tau_{1}$ and $\tau_{2}$. The yellow lines and red and green planes correspond to the baseline values $\tau_{1}=2.5 \times 10^{-10}, \tau_{2}=1.0 \times 10^{-9}$, $S_{0}-S_{\infty}=157,000,000$. The final size $S(0)-S_{\infty}$ decreases greatly as $\tau_{1}$ decreases and as $\tau_{2}$ decreases. 
medRxiv preprint doi: https://doi.org/10.1101/2020.05.28.20116103; this version posted June 12, 2020. The copyright holder for this preprint (which was not certified by peer review) is the author/funder, who has granted medRxiv a license to display the preprint in perpetuity.

It is made available under a CC-BY 4.0 International license .
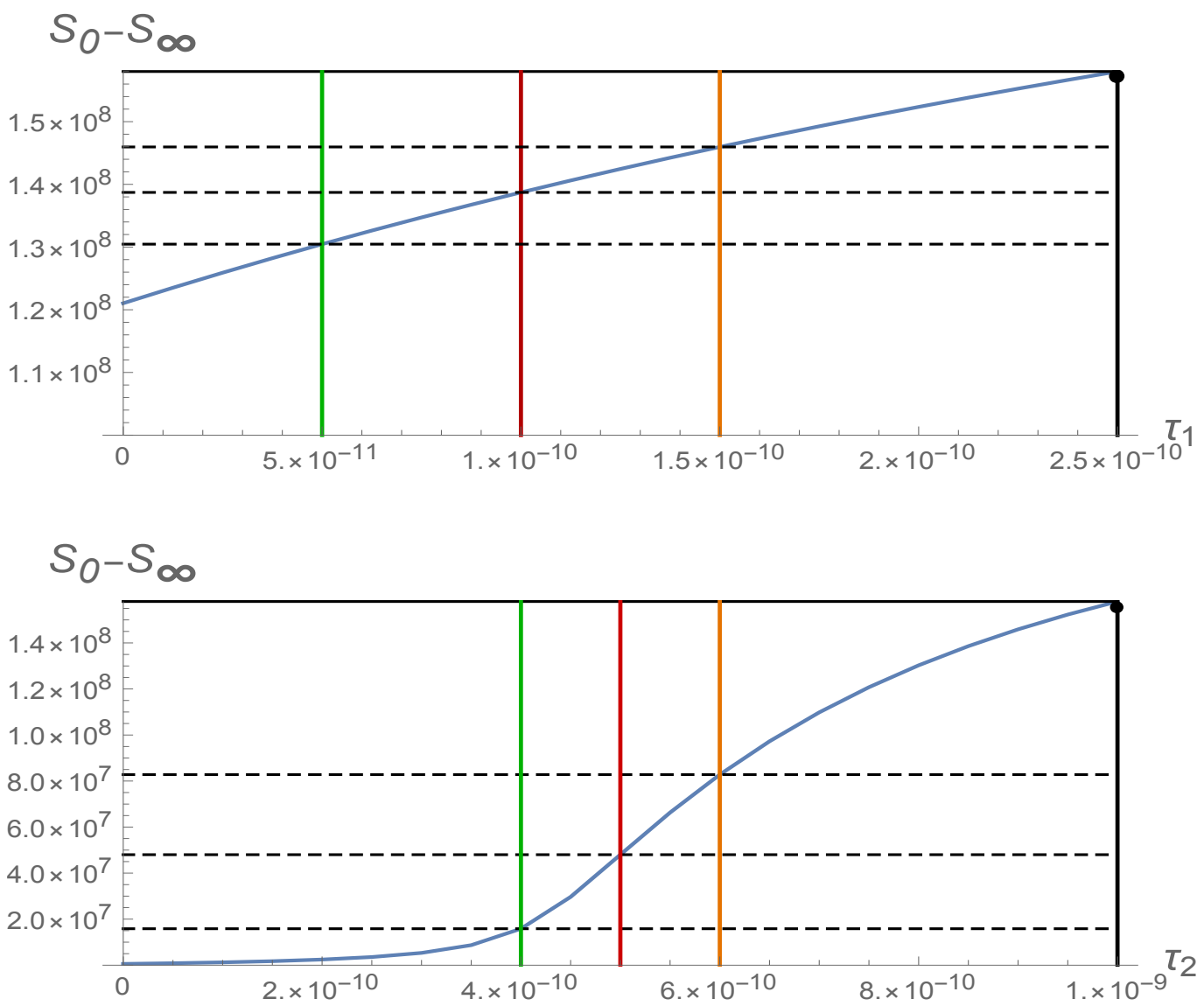

Figure 6: Blue surface: final size $S_{0}-S_{\infty}$ graphed as a function of $\tau_{1}$ and $\tau_{2}$. The yellow lines and red and green planes correspond to the baseline values $\tau_{1}=2.5 \times 10^{-10}, \tau_{2}=1.0 \times 10^{-9}, S_{0}-S_{\infty}=157,000,000$. The final size $S(0)-S_{\infty}$ decreases greatly as $\tau_{1}$ decreases and as $\tau_{2}$ decreases. For $\tau_{1}=1.5 \times 10^{-10}$ and $\tau_{2}=0.6 \times 10^{-9}$, the final size $S(0)-S_{\infty}$ is approximately $38,000,000$. 
medRxiv preprint doi: https://doi.org/10.1101/2020.05.28.20116103; this version posted June 12, 2020. The copyright holder for this preprint (which was not certified by peer review) is the author/funder, who has granted medRxiv a license to display the preprint in perpetuity.

It is made available under a CC-BY 4.0 International license .

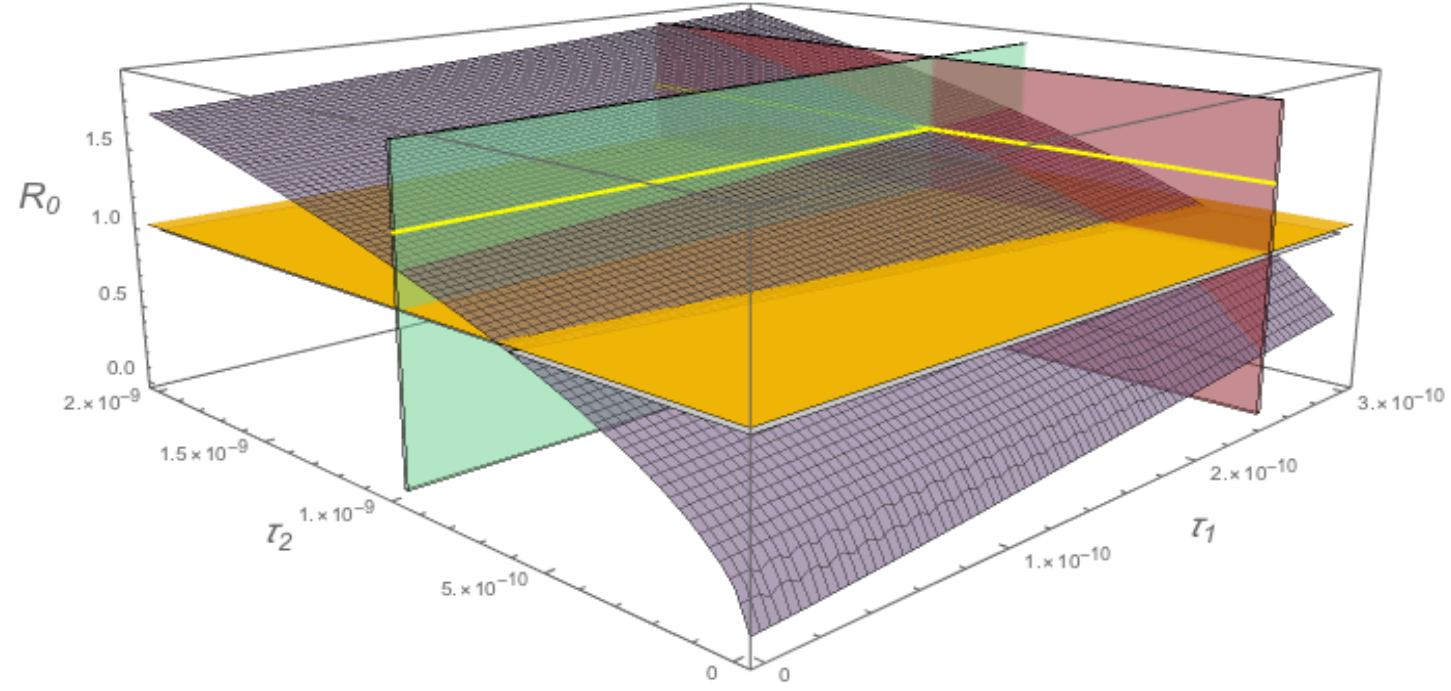

Figure 7: $\mathcal{R}_{0}$ as a function of the transmission parameters $\tau_{1}$ and $\tau_{2}$. The yellow lines and red and green planes correspond to the baseline values $\tau_{1}=2.5 \times 10^{-10}, \tau_{2}=1.0 \times 10^{-9}$. The orange plane is at $\mathcal{R}_{0}=1.0$. At baseline, $\mathcal{R}_{0}=1.41$. The epidemic transmission is mitigated if $\mathcal{R}_{0}<1.0$. 